\title{
Greening as a Factor of Transition to Sustainable Development in Coal-Mining Regions
}

\author{
Irina Kudryashova ${ }^{1, *}$, and Kirill Korsakov ${ }^{1}$ \\ ${ }^{1}$ Plekhanov Russian University of Economics, Kemerovo branch, 650992, 39, Kuznetskiy prospect, \\ Kemerovo, Russia
}

\begin{abstract}
The article is devoted to solving the problem of environmental pollution, which is one of the main negative factors of economic development in the coal-mining regions of the Russian Federation. The study of theoretical and practical approaches to the formation and implementation of the mechanism of greening at the level of subjects of the Russian Federation and their municipalities, the comparison of the definitions of "greening of the economy" and "greening of the regional economy", "greening of production (enterprise)" in a multi-level context, taking into account the differentiation of the scale and instruments of environmental policy. A multi-level and multi-criteria approach to the study of the process of greening, the formation of ecological and economic mechanism of functioning of coal-mining regions, taking into account the processes of localization and globalization. It is proved that greening is the most important factor in ensuring the transition to sustainable development of coal-mining regions, and economic growth involves an inextricable combination of economic and environmental management.
\end{abstract}

\section{Introduction}

Environmental pollution is one of the main negative factors of economic development today. This problem exists in many countries of the world, and the Russian Federation is no exception, as the mining, metallurgical and petrochemical industries constitute a high proportion of Russian industry.

In Russia, environmental problems are especially acute in regions with large industrial centers. Thus, according to the results of the National Ecological Rating of the Regions of the Russian Federation for 2018, which was compiled by the authoritative All-Russian organization Green Patrol, the traditional outsiders are: Sverdlovsk region, Chelyabinsk region, Irkutsk region, Moscow region and Nizhny Novgorod region [1].

According to the Ministry of Environment, currently in the cities of the Russian Federation, in some cities, the air pollution index can be characterized as exceeding and considerably exceeding the limits of the norm. On average, in our country more than $17 \%$ of the population is affected by high levels of air pollution.

\footnotetext{
*Corresponding author: kudrina2007@mail.ru
} 
The second most serious environmental problem in the regions of Russia is the high level of water pollution. According to the Federal Service for Hydrometeorology and Environmental Monitoring (Roshydromet) in 2016, about 3 thousand reservoirs with a high and very high level of pollution were registered. According to experts, surface waters in 53 regions of Russia remain polluted or extremely polluted to this day [2].

The problems of ecologization are very important for coal-mining regions, which, in particular, is noted in the "Strategy for the Development of the Kemerovo Region until 2035", while the environmental component should be the basis for the development of industry, in particular, coal. Today, the level of environmental quality in the Kemerovo Region is at a potentially dangerous stage of its development for society. The depletion of the natural resource state of the country endangers the livelihoods of the state, society, man. At the present stage, despite the colossal achievements in the field of scientific and technological progress, the technologies used in production are still far from the status of "waste-free" natural processes. Industry, transport, energy create a huge amount of emissions and waste, which for the most part remain unprocessed. Secondary waste products of enterprises cause material damage to the state, which, according to incomplete data, is quite large.

\section{Materials and methods}

The recently established concept of sustainable (non-destructive to nature) economic growth implies an inseparable combination of economic and environmental management.

The degree of environmental pollution can be determined using quantitative and qualitative indicators. Quantitative indicators reflect the immediate scale of pollution (the volume of emissions of harmful substances into the atmosphere, the volume of waste discharged into open water bodies). Qualitative indicators of environmental pollution show accumulated damage caused by anthropological factors, and are determined by indicators such as the atmospheric pollution index (API) and the specific combinatorial index of water pollution (UKIZV), showing the level of pollution of surface waters. The environmental situation within specific areas can also be assessed using specific indicators: the ratio of emissions and discharges of harmful substances to the results of economic activity.

According to Russian researchers N.V. Belyaev and E.A. Ilinbaeva, in order to solve the above problems, it is necessary to strengthen the state policy in the field of regional environmental management, namely to ensure:

- a clear and transparent delineation of powers for environmental quality control at the federal, regional and municipal levels of government;

- gradual transition to international standards of production and active research and development to improve the environmental safety of the population of the regions of Russia;

- toughening fines for environmental offenses and for environmentally hazardous activities, as well as strengthening the role of public expertise of projects and government programs;

- the organization of economic regulation of the market system in order to stimulate business entities to introduce environmentally friendly methods, technologies and production processes [3].

Leading expert in environmental activities S.Yu. Savon, argues that the main mechanism for improving the ecological state of the economy, which can benefit the regional authorities, is to support industrial enterprises, whose activities do not entail harm to the natural environment. This mechanism can be implemented using the method of "rewards" and "penalties". On the one hand, this is an increase in the tax burden on those enterprises where environmentally hazardous products are produced, especially for regions 
with extreme environmental pollution, as well as regions with alternative economic development options. On the other hand, this is the provision of tax benefits to enterprises that promote a clean economy policy and use environmentally friendly technologies [4]. Stimulating measures are targeted tax breaks, such as deferring tax collection, reducing income taxes by the amount the company intends to spend on reducing the environmental impact of its production, reducing the VAT rate, and introducing the practice of accelerated depreciation of fixed assets for environmental purposes and environmentally friendly equipment.

The introduction of optimal technological systems that operate on the principles of lowwaste within a single region, also significantly reduce the environmental burden in the territorial context. Production waste is unused material, energy for which labor has already been expended. That is why non-waste production makes it possible, without significant anthropogenic pressure on the environment, to increase production volumes of final products. A striking example of a waste-free technological system is the production of iron and non-ferrous metal concentrate in the city of Mtsensk, Oryol Region. Employees of the National Research University "MISiS" and the company "Vtoraluminprodukt" put into operation the newest innovative furnace that can produce the necessary metal from recycled materials, which is formed at the same plant, in the manufacture of iron in the traditional way [5].

However, up to the present, the tools and procedural and instrumental support for the development and implementation of the greening mechanism in Russia and its regions have not been systematically worked out. Such scientific results, brought to the level of methodological developments suitable for practical use, could contribute to the formation of a national resource-environmental policy based on the generation of spatial knowledge, an intensive type of reproduction, resource-saving technologies, taking into account international practice of environmental protection.

The foregoing actualizes the study of theoretical and practical approaches to the formation and implementation of the greening mechanism at the level of the subjects of the Russian Federation and their municipalities, as well as the development of recommendations for improving its effectiveness and efficiency.

The fundamental scientific task is to search for the essential interrelation of the categories "environmental management mechanism" - "greening production" - "compliance with international norms and rules in the environmental field" - "optimization of resourceenvironmental policy in the Russian Federation and its regions" - "adequate environmental protection tools", as the basis of the paradigm of sustainable development of territories.

Ecologization of the economy is considered as a set of legal, organizational, managerial, financial, economic and technological measures using intensive technologies for processing natural resources aimed at developing the economic potential of a country or region based on reducing pressure on the environment while maintaining production goals making profit with sufficient the pace of economic development. The main goal of greening the economy is aimed at balancing economic development and the integrated use of natural resources, creating processing products based on the concept of value chains, restoring the natural environment and reducing anthropogenic influence on the natural environment.

Greening the economy includes legal, managerial, financial, humanistic and technological aspects, the main ones of which are:

- legal support based on international and federal legal acts, the system of environmental law, the regulatory framework, a systematic assessment of the level of environmental • damage and the restoration of environmental quality;

- the system of administrative legal and economic levers of influence on environmentally hazardous enterprises, formed on the basis of federal and regional legal acts; 
- strategic management of the integrated development of the regions based on an environmental approach that implies the rational and balanced use of natural resources; - greening public awareness, raising the level of environmental education of the management system at all levels - from company managers to working personnel;

- strict adherence to environmental standards by industry and agriculture throughout the entire product life cycle, from the design stage to the liquidation stage of the enterprise; - improvement of the system of financial and economic incentives for enterprises, ensuring the profitability of reducing pollution of the environment by the enterprise, as well as its transition to "clean", waste-free production;

- development of the market for environmental business and environmental services using the tools of economic incentives from state and municipal authorities (environmental engineering, auditing, trading, consulting);

- creation and implementation of the latest innovative resource-saving technologies, focused on the technology of "closed loop" and "clean" production.

Ecologization involves the process of steady and consistent implementation of technological, managerial and other systems that allow for increasing the efficiency of using natural resources and living conditions of the population along with improving or at least preserving the quality of life.

According to the authors, it is advisable to consider comparing the definitions of "greening the economy" and "greening the regional economy", "greening production (enterprises)" in a different level context, taking into account the differentiation of the scale of environmental policy implementation.

Based on the studies of Russian and foreign scientists, the authors attempted to characterize the functioning of the ecological system in the context of globalization from the positions of a multi-level nature at the international, national and supranational levels.

It should be noted that the development of a modern ecological and economic mechanism for the functioning of territories is impossible without taking into account international norms and rules.

Theoretical substantiation of the functioning of the ecological system in the context of globalization from the standpoint of its different levels, in our opinion, essentially depends on the nature of the ecological-economic relations and the activities of the institutions of environmental administration, which act as a synthesis of the economic, legal and institutional components of its functioning mechanism. To substantiate the different levels of building an ecological system in the context of globalization, we have identified the following or criteria:

- Extent of territory coverage;

- The scale of institutionalization in the environmental field;

- Nature of the functioning of the ecological system;

- Priority of the objectives of the ecological system.

The first of these (the degree of coverage of the territory) can be considered in a narrow sense, in the context of the implementation of environmental protection measures within the territory of a particular state and its regions, i.e. at the national and regional levels, for example, across the Russian Federation and subjects of the Russian Federation. On the other hand, in a broad sense, this means expanding the greening system, taking into account the coverage of the territories of several states as part of an integration group, for example, the EU, the CIS, the EAEU economic union, etc., which implies the need for a supranational level within a single ecological system of integration.

The next criterion associated with the scale of institutionalization in the field of environmental activities involves the fact that the environmental system of the national level, for example, at the level of the Russian Federation, the implementation of environmental and economic processes, first, is the main institutional protection institution 
- the Ministry of Natural Resources and Ecology of the Russian Federation (Ministry of Natural Resources of Russia), and secondly, is carried out using the main instruments of environmental policy.

At the same time, the supranational level means that there are actual and implemented bodies in the environmental sector, jointly established by the member countries of the integration grouping, in particular, such as the EU Commission, the Department of Industrial Policy of the Eurasian Economic Commission (EEC) of the EAEC. The third criterion is the nature of the functioning of the environmental system - is largely due to the previous, the distinctive feature of which is an institutional component, in connection with the national level, environmental activities is carried out on a legislative basis of a particular state in the interests of environmental protection in the territory of a particular state. Unlike it, the supranational level requires the formation of unified unified approaches from the Member States of the Integration Group in accordance with international standards and requirements for the further expansion of its participants and territories by joining other States. This means that it is based on a fundamentally different system of regulatory regulation, which is extended for national limits with a partial refusal of national sovereignty in certain areas. For example, in Russia since 2002.

In the framework of the national environmental system, the legislative framework in the field of environmental activities was: Federal Law 10.01.2002 N 7-FZ "On Environmental Protection", the Russian Federation of 21.02.1992 N 2395-1 "On the Subsoil", Federal Law No. 81-FZ of 20.06.1996 NCO "On state regulation in the field of production and coal use, on the features of social protection of workers of the coal industry organizations" and a number of other normative legal acts.

At the supranational level of examples of cooperation in the field of environmental development, under the leadership of the Industrial Policy Department of the Eurasian Economic Commission (ECE), became:

- Creation and the functioning of the Eurasian Technological Platform (ETP)" Environmental Development Technology";

- Initiation and the implementation of cooperative projects on the formation of scientific and production consortia;

- Development of the Internet portal of the best environmentally effective, energy and resource-saving solutions and technologies [6].

These tools are an integral part of a unified concept of the creation and functioning of the Eurasian network transfer technology in the field of nature management and elements of the environmental system on an over-level level and can become interesting and useful not only by EAES, and to third countries.

The multiplicity of the globalization factors, the most complicated under the influence of the last conditions of the management, the impossibility of purely market self-regulation in this situation and, especially, in a planetary scale, predetermine a special role in this process of macroeconomic regulation. On the one hand, the main principle at the level is acquired by the targeted efforts to overcome, weaken and eliminate obstacles and restrictions in the environmental sector, on the other - promote the globalization processes, implementation of consistent measures to coordinate economic and social programs, resource resources for solving global problems affecting the world community, groups of countries, regions.

The most important example of global regulation in the environmental sphere is an attempt to develop and operate the mechanism for the emission of emission in the international scale (at the same time the Kyoto Protocol, then - within the framework of the Paris Climate Agreement) to comply with the balance between the need to reduce greenhouse gas emissions and the right to use fossil fuels. 
In our opinion, the formation and functioning of the environmental system in international, supranational, national, regional, municipal and microvolutions should be carried out in accordance with the following principles:

1. Strengthening the global response to the threat of climate change in the context of sustainable development and regulation of environmental activities by international institutions of the world and supranational level.

2. Unification of international, national standards in a single way to integrate in various fields: environmental, schemes of labor protection and security, quality management systems, etc. in order to reduce the load on the ecosystem.

3. Harmonization and synchronization of the national regulatory environment in the field of environmental protection of various countries of the world on an over-level level.

4. Unification of national environmental policies in order to optimize the environmental situation, taking into account complementary and compliance not only national, but international norms in the environmental sector.

5. Standardization of environmental management systems in enterprises (organizations), taking into account not only national but also international standards.

6. Robbery and harmonization of national environmental regulations and strategies in the field of environmental problems.

The ecologicalization of the regional economy involves the formation of a socioecological and economic system aimed at improving the controllability by territorial nature management based on the effective use of the mineral and raw material complex of the region based on complex processing of raw materials. The ecologicalization of the regional economy is based on the national concept of environmental activities taking into account regional features. In the field of economic policy conducted in the regions, one of the reasons for the eraits of environmental problems is underestimation of real damage to environmental pollution, which leads not only to distortion of economic development indicators, but also leads to the adoption of inefficient management decisions that cause depressiveness in the development of the region, negative migration levels.

To improve the ecology of the regional economy, several strategies can be used, which can be applied both at the regional and state level:

1. The legal strategy is the adoption and regulation of regulatory documents related to environmental aspects in the economy. Periodic review of legislation in the field of environmental development.

2. Economic strategy is the creation of economic instruments that in practice would have to be striped by the Enhancement of environmental and economic activities. It is necessary to improve the system of financing environmental activities, involve foreign investment in order to improve environmental safety.

3. A personnel strategy is to ensure the professional training of new and retraining of existing personnel in the field of environmental safety and environmental management, as well as the active transfer of knowledge of the environmental economic development of the region. Innovative strategy is the promotion of new development and products that meet international standards (for example, such as ISO 14000). Interaction of universities with enterprises for the creation and implementation of new ways of improving production from the environmental point of view, as well as support for new projects in the field of Eco business.

4. Marketing strategy is the development of the market of services that contribute to environmental safety. Propaganda of Environmental Such Activities, by various forms of advertising through the media.

Analysis of approaches to the consideration of the ecological proceedings process has to come to the conclusion that most authors invest in the concepts of the "Ecological System" 
and "Ecological and economic mechanism" clearly expressed general-likeary and the possibility of its functioning on a national scale and at a subfederal level.

In our opinion, these concepts should be considered in a broader scale and in a diverse context: not only within the framework of government in a narrow sense - at the national, regional, municipal levels, but also in a broad sense - in an international scale, which promotes the creation of favorable conditions for environmental activities in the world and an effective solution of such a global problem as environmental. This is evidenced by the appearance of domestic scientists in the works (such as Bobylev S.N, Khodjaev A.Sh. and others) of concepts associated with the expansion of the scale of the functioning of the environmental mechanism that expands such a definition as "economic nature mechanism", understood as an integral part of the "global economic mechanism" formed "on-sequential, inter-industry and interregional basis" [7, 8].

Despite the diversion of the interpretations, in almost all there are no multi-level analysis of the ecological process, which narrows the range of study of its cause-effect relationships and environmental relations at the present stage.

At the international level, the main problem is to create a model of the world device that does not contradict the principles of sustainable development that allows the world community to comprehensively solve the world-wide global environmental, demographic, social, political tasks, fighting limited resources, criminality, international terrorism, etc.

At the national level, we are concerned about the problems of involvement of Russia in the system of world-wide relations, strengthening its status, solving issues of national, economic, environmental safety, problems of building a holistic geopolitical and geostragis development.

At the regional level there is a problem of sustainable development of the region in the context of globalization as a subject of the Russian Federation or municipal formation, the problem of choosing its economic niche and strategy, using the available resource and scientific and technical potential. To stand in conditions of cardinal structural changes all over the world and within the country, to respond adequately to calls to globalization, the register has the problems of finding competitive advantages of the higher order, the task of social protection of the population from the costs of globalization, ensuring environmental safety and stable growth of the main indicators of the standard of living in the region.

Within the framework of the environmental policy environment, the environmental activities is multiplication and provides in the state the implementation of functions on:

- compensation for negative environmental consequences of economic development;

- stimulating the development of ecologoslabred and environmental measures and production;

- suppression of irrational use of resources in the direction of economical use and reduce the environmental load; environmental control and monitoring of environmental protection of enterprises.

In the context of the creation of conditions that promote the solution of environmental problems and modernization of the economy of the Russian Federation, defined as priority areas of the country's strategic development, enshrined by international norms and regulations, in our opinion, adding new features that are important for participants in economic activities - nature users, taking into account the changing domestic and external conditions.

Pollution of the environment is an important problem in number of countries engaged in active industrial activities. In no case can not leave this problem without due attention, because The consequences in turn can be colossal. Based on the main environmental indicators that determine the level of environmental pollution, the main environmental problems should be identified for specific constituent entities of the Russian Federation. To resolve environmental problems, timely and high-quality strategies are needed, which will 
be able to positively affect the ecology of the country's economy. In its own way, it is necessary to understand that the problems associated with ecology do not concern a separate country or region, they cover the whole world and should be considered from the point of view of world practice.

\section{Results and discussion}

In order to ensure the effective functioning of the ecological system at the national and regional levels in the context of globalization, the use of traditional forms and methods of environmental management is insufficient; therefore, it is necessary to use the new tools of the ecological and economic mechanism for the functioning of coal-mining regions in the modern information technology base to minimize negative environmental impact, taking into account compliance with the rules and regulations, Botha international institutions in addressing environmental issues on a global scale.

The desire of territories with single-source economic development towards balanced environmental regulation was considered by the authors in the context of the concept of globalization of the economy, i.e. "Embedding" characteristic global and local aspects into traditional approaches to solving the problems of human ecology in the formation of regional environmental policy.

As a result of the study of the theoretical foundations of the greening process in coalmining regions in the development of the ecological-economic mechanism, it was proposed and justified to use a multi-level approach taking into account localization and globalization processes.

The indisputable advantages of the proposed approach include its multi-level nature, which allows a differential assessment of the effects of anthropogenic pressure in the context of globalization and the local implementation of an adequate environmental policy at supranational, national, regional, municipal, cluster and micro levels in conjunction with sustainable development of territories and taking into account human adaptation to harmful natural and man-made factors.

The formation of the ecological-economic mechanism of functioning of mineral-raw material clusters to ensure the sustainable development of the mining regions at the level of the constituent entities of the Russian Federation and their municipalities should be primarily aimed at minimizing the negative impact on the environment, compliance with international standards in the environmental field in the context of global development.

The projected environmental-economic mechanism should provide a preliminary environmental impact assessment, focus on long-term programming of environmental activities, and mainly use the basic tools of environmental policy: direct regulation, market regulatory tools and voluntary programs.

The scientific novelty consists in the development of the theory and methodology of the formation of the ecological-economic mechanism of functioning of the coal-mining regions of the Russian Federation to ensure the sustainable development of territories based on a multi-level approach, taking into account localization and globalization processes.

The results of solving this fundamental scientific problem can provide a basis for the development of a new knowledge branch of the science of globalization, which allows studying environmental protection activities in the context of parallel studies of globalization and regionalization, as well as globalization and greening of the global, national and regional economies. 


\section{Conclusions}

The desire of territories with single-source economic development towards balanced environmental regulation was considered by the authors in the context of the concept of globalization of the economy, i.e. "Embedding" characteristic global and local aspects into traditional approaches to solving the problems of human ecology in the formation of regional environmental policy. Based on the research conducted, the authors substantiated a theoretical and methodological multilevel approach to the ecologization of coal mining regions taking into account world practice, based on the theory of globalization of the economy, to ensure the sustainable development of territories in the mining regions of the Russian Federation in conjunction with the sustainable development of territories manmade factors.

\section{References}

1. Environmental rating of subjects of the Russian Federation (EARF, Moscow, 2015)

2. A report on the peculiarities of climate on the territory of the Russian Federation (EARF, Moscow, 2016)

3. V. N. Belyaev, E. A. Ilinbayeva, Greening of socio-economic development of Russian regions as a tool for the implementation of state policy in the field of environmental management (Infra-M, Moscow, 2014)

4. D. Yu. Savon, Greening of the production sector as the basis of innovative sustainable development of the region (Piter, Sankt-Peterburg, 2017)

5. In Russia, a new installation of waste-free production of ferrous and non-ferrous metallurgy (EARF, Moscow, 2015)

6. A. A. Niyazova, E. F. Sadykova, Modern problems of science and education, 1, 77-82 (2013)

7. S. N. Bobylev, A. S. Khodjaev, Economics of nature use: textbook (MSU, Moscow, 2013)

8. Environmental development of the EAEU received the first projects (EARF, Moscow, 2016) 